\title{
Cultivating Social Innovations: Lessons from the Bangladesh Case
}

\author{
Zulker Nine1, Hongyi Chen² \\ ${ }^{1}$ Maritz Consulting Group, Minnetonka, MN, USA \\ ${ }^{2}$ Mechanical and Industrial Engineering Department, University of Minnesota Duluth, Duluth, MN, USA \\ Email: honchen@d.umn.edu
}

Received 21 April 2016; accepted 13 May 2016; published 16 May 2016

Copyright (C) 2016 by authors and Scientific Research Publishing Inc.

This work is licensed under the Creative Commons Attribution International License (CC BY).

http://creativecommons.org/licenses/by/4.0/

c) (i) Open Access

\begin{abstract}
Despite the social and economic challenges, Bangladesh has shown significant improvement in the basic condition of people's lives in the past twenty years. The dramatic change lies in the success of many innovations happened in different sectors of the Bangladesh society. In the healthcare sector, projects such as the community health service program greatly improved the health of rural people, especially the maternal and children, in creative ways. These social innovation projects, usually initiated and implemented by non-government organizations throughout the history, have become an inherent part of rural life and played a big role in the economic empowerment of Bangladesh. By examining the environment and process of these social innovations, we draw a valuable lesson to shed lights on how social innovations can be best cultivated to improve the welfare of the affected population.
\end{abstract}

\section{Keywords}

Social Innovation, Non-Government Organization, Bangladesh

\section{Introduction}

The concept of innovation is widely discussed and framed in the fields of technology, management, economics and other areas of sciences, although many researchers have found innovation as a social action [1]. Social innovation, which brings changes in nature and practices in a society as an institutionalized form, is a key element of social development. As old as mankind, the concept of social innovation has come to lime light after Md. Yunus was awarded the Noble peace prize in 2006 jointly with Grameen Bank (GB) for his revolutionary social innovation in microfinance [2]. Even if we look back in time, we will see that all practices, norms and habits of today such as money, law, states, festivals, currency etc. were social innovations at a certain time. Although not 
all social changes are social innovation, with proper planning, goals and objectives, any new social initiative can be an innovation if coordinated by social agents [3]. This was exactly what happened in the health sector of Bangladesh back in the 1970's when the government encouraged community based health service programs to fight small pox and malaria. Before launching the program, the country was suffering in child and maternal health cares and had a neonatal mortality rate of 24 per 1000. This program has changed that scenario by connecting the rural people with modern healthcare [4]. The sustainability and the adoptability were unique features for this program. The community health program workers were trained to go door to door to raise awareness regarding family planning, child nutrition, vaccines and many child diseases along with maternal health issues among the community members. In this article, we analyze projects such as the community health service program in Bangladesh in the context of social innovation. By looking at the process of how these projects succeeded and the environment within which they happened, we hope to draw a lesson on the key factors that contribute to the success of social innovations.

\section{Social Innovation}

\subsection{Definition and Driving Factors}

Defined as "the process of inventing, securing support for, and implementing novel solutions to social needs and problems" [5], social innovation is the outcome of a social change and is usually administered by a social agent. Unlike technological innovations whose impact is more on a certain company or an industry, social innovations always aim at collective changes in society [2]. When knowledge and resources are exchanged and shared between the agent and social institutions, the need for a social change inspires and is realized through innovations. The concept of social innovation was being confused with technical innovation until sociologist William Ogburn first noted the distinction between them. He described the introduction of 'League of Nations', different religious rituals and other social processes as a social innovation and tried to clear the confusion [6]. Moreover, during the last two decades, the term "social innovation" was discussed in different fields of studies like social entrepreneurship, social movements and social economy [7]. It is only in the recent past that study and discussion of social innovation was popularized after more scholars started to realize the broader sources of social innovations and their impacts. Howaldt and Schwarz identified a wide variety of sources for social innovations including web-based social networking, new business and logistic models, social movements (gender mainstreaming) and so on [2].

One of the central questions to ask when studying a social innovation is "what factor(s) motivate such an innovation?" The answer has been perceived differently by different researchers. Some focused more on the social changes or the need for change as the key motivating factor of a social innovation [2] [8], while others described social innovation as an effective, efficient and sustainable solution for a social problem [5]. However, regardless of whether the change is viewed as the solution or the trigger, based on the nature and iteration of the innovation process, it is clear that a social problem is present in the event of social innovations. When the goal has been set as a collective well-being, the first thing that comes to attention is a social problem and then a way to solve it.

The driving factors for social innovations differ from the ones for technological innovations. As discussed earlier, social change is the main objective for a social innovation; therefore it acts as one of the main driving factors. This unique nature has given social innovations an immaterialist face [2]. In technological innovations that deal with products and services, performance is evaluated mainly on the creation of economic value [9]. Profit and commercialization success drive the technological innovations. In terms of social innovations, value creation and social welfare play important roles in the driving force, and success comes out as social practices and norms rather than in any materialistic form. In addition, in technological innovations, "modularity" is considered as the heart of diverse advancement [10], whereas "social behavior and structure" is the core driving factor in social innovations [11]. Moreover, when it comes to social development, new research findings show that social innovation is closely related to technological innovation [11].

\subsection{Framework of Social Innovations}

In the review article, Phills Jr. et al. discussed two important terms, "social entrepreneurship" and "social enterprise," in comparison with social innovation. They concluded that most social entrepreneurship studies had focused on the personal qualities and traits of a social entrepreneur while studies on social enterprise mostly inves- 
tigated organizational supports in terms of finance and operations [5]. Both the entrepreneurs and the organizations belong to a social system and are vital components of social innovations. The underlying objective of social innovation is to create social value, and value creation is an iteration process between these two components. A successful and visionary entrepreneur realizes a social problem and creates a value chain through an enterprise. This is how the human component and the organizational component work with each other to create social innovations that establish a bridge between the value and the social problems.

To understand the complexity and success of social innovations, we need to understand the social innovation process first. A comprehensive framework that helps us illustrate the process clearly was developed in [2]. The framework combines the structuration and the institutional theory of social innovation, and includes three main actors: agency, institutions and social systems. These three actors are in a close relationship throughout the innovation process and act as a chemical solution to impact on each other and the whole process. Agency is the acting element or actor of the innovation process that can be compared to the enterprise or the entrepreneur. Agent acknowledges the social need and interacts with social systems and institutions through "reflexivity" to understand the process parameter. "Reflexivity” is an agent's capability to monitor the social responses [2]. Institutions are different social units like families, educational institutes, religious organizations, business, health sectors etc. Finally, social systems are the collective norms, habits and the overall culture of a society. A social system consists of different groups of interests and interact with each other at various levels [12]. In the innovation process, the agent communicates with the institution regarding the new idea or change and initiates the channel of change. Institutions are an integral part of the whole social system, and through legitimate action the information is passed to the system. The components of the social systems consisting of different groups iterate the process and make it a practice in all levels. This is how a social innovation process is completed normally [2].

To understand the factors that contribute to successful social innovations, we examine several social innovations happened in Bangladesh with a focus on the healthcare sector. The examples were chosen due to their dramatic impacts on the overall health improvement to community people and the role they played in changing the rural life in Bangladesh. Through studying the environment and process of these successful social innovations, we hope to draw a lesson and shed lights on how social innovations can be better cultivated.

\section{Social Innovations in Bangladesh Healthcare Sector}

Bangladesh is one of the world's most densely populated countries with a large population living in poverty. However, after the country was born, it developed rapidly in its health care sector despite of several limitations. The success rate in both child and maternal health care, comparing to other South Asian countries is promising. By the end of year 2013, Bangladesh people had "the longest lift expectancy, the lowest fertility rate, and the lowest infant and under-5 mortality rates” in south Asia, even though its overall spending on health care was less than several neighboring countries [13].

The success and growth in the health service of Bangladesh is a direct outcome of a social innovation-the community based health program. This program has enabled the country to reach out to each and every village and union and helped the policy maker to initiate root level health programs. The journey was difficult as the health workforce is substantially smaller in Bangladesh with a rate of 0.58 per 1000 population. But with the help of government and non-government organizations (NGOs), trained community health workers grew dramatically and are mobilized to visit door to door in order to counsel and raise awareness among mothers. Data show that there are more community health workers in Bangladesh than neighboring countries such as India or Pakistan [14]. In years 2011 to 2012, there were 219,000 community health workers in Bangladesh, among which 56,000 were government workers and 163,000 were from the NGOs. Before we discuss details on how this social innovation succeeded in Bangladesh, we first give a brief overview of the healthcare programs and the NGOs in Bangladesh.

\subsection{Overview of the Healthcare Sector and NGOs in Bangladesh}

The healthcare service structure in Bangladesh has been developed as a mix between governmental and private contributions. Due to administrative purpose, the country of Bangladesh is divided into six divisions, which are further divided into 64 districts, and then 460 sub districts that are called upazillas, and then 4451 unions at the bottom level [15]. Accordingly, the health care sector administered by the Ministry of Health and Family Wel- 
fare includes three levels, where there were 35 teaching and specialized hospitals, 59 district hospitals and 425 upazilla health complexes, as of year 2013 [4] [16]. At the base level of the health care structure, initiated and operated mainly by NGOs such as BRAC, 18,000 community clinics employing 56,000 health workforces mainly serve the poor and rural community people. Nowadays, these community clinics keep expanding and aiding the healthcare facility while acting as a major building block in the healthcare sector of Bangladesh. They are also acting as a community change agent that develops and re-innovates the social life.

Due to Bangladesh government's "unusual friendly" relationship with NGOs [17], there are currently 800 NGOs serving the Bangladesh people. Among them, BRAC, OXFAM, and Action Aid Bangladesh are the pioneer ones, and BRAC and GB are regarded as the flagship NGOs [18]. Together, all these organizations account for 163,000 community workers in the country with a ratio of 13.7 per 10,000 people [4]. BRAC, an NGO that started as a small social relief project distributing emergency aid for victims from the independence war, is recognized as the largest NGO in the world judging by the number of employees since 2012 [17]. Based in Bangladesh, BRAC now operates in all 64 districts of the county as well as 13 other countries in Asia, Africa, and the America. With the "simple yet radical" idea to bring poor people in poor countries together to share resources and train them to start their own business [19], BRAC does practically everything ranging from health care to primary education, food processing, financing, legal, and so on [17]. In the health care field alone, BRAC had 11 ground-breaking programs running since 2006, covering almost $90 \%$ of the population in Bangladesh [20].

\subsection{Social Innovation Examples in the Healthcare Sector}

Community based healthcare service was approached due to the overcrowded population and lack of established hospitals and medical facility in remote rural areas of Bangladesh. Before the establishment of the community health services, most of the public and private health care development concentrated mainly in urban areas, leaving nearly $75 \%$ of the population which is in rural areas uncovered [18]. Due to reasons such as difficulty to retain doctors, unfriendly behavior of the healthcare providers, and unofficial fees being charged in upazila health complexes, local people mostly avoid them but seek help from private healthcare providers with no formal medical qualifications [21]. To solve the problem, BRAC first trained a few male paramedics to deliver minor treatment for common illness in 1970s [4]. Nowadays, both male and female community health workers are hired and trained for wide ranged treatments. These community health workers act as foot soldiers and visit door to door to raise awareness regarding the child mortality, birth control, usages of contraceptive pills, sanitary napkins, iodized salt, hygienic soap, pneumonia, diarrhea and infectious diseases. They are also trained as paramedics to support primary treatments.

"Reading glasses for improved livelihood", an simple yet powerful project as part of the BRAC's "eye care interventions" program, was designed to support rural women who are suffering from "Presbyopia", an eye related problem that occurs naturally due to aging [20]. In rural areas, women play a major role in managing the family and control all the household related issues. Presbyopia in women causes trouble and ceases all the household efforts. To solve the problem, the community workers in this program distribute reading glasses in exchange of a nominal fee. These glasses are normally used for reading and to do near sighted works like sewing, weaving, handcraft making, etc. With the glasses, those women can be more productive and self-empowered. The community clinics and workers are not only spreading the healthcare facility to rural people but also try to ensure sustainable health in the communities. For example, while distributing the glasses, the community workers also check for other eye related problems and if necessary advise the patient to consult with doctors. Because of the program, 48\% of the suspected patients were treated in 2006 [20]. Through the mobilization of the community health workers, the community health service has also changed and empowered the rural communities.

Another life changing project undertaken by BRAC is the Micro Health Insurance (MHI) program it jointly funded with the International Labor Organization (ILO) for the deprived rural people. Due to poverty, the fear of cost and the lack of government financial support, many people in rural areas, especially women, do not have access to healthcare service. The MHI program provides primary medical and pathological facilities to the selected members in two pilot projects in Bangladesh. With a yearly fee of only BDT 100 (USD 1.25), rural women can afford the use of primary health checkup facilities nearby.

Besides BRAC, two other NGOs, Grameen Kalyan (GK) and Society for Social Services (SSS) also devel- 
oped similar MHI programs in the late 1990s and early 2000s [18]. As mentioned earlier, GB is a major NGO that gained great reputation by developing the microfinance program in Bangladesh to provide collateral free loans in small amounts to enable poor people, especially women, to develop household-based micro enterprises [21]. Despite of the popularity and proven benefits of the microfinance program, a group of poor people who experience reduced work capability due to sickness and not being able to afford healthcare are excluded as beneficiaries. To help these vulnerable people who are the poorest poor and let them benefit from the microfinance program, the founder of GB added a MHI program by founding anon-profit company GK in 1996 [22] to prevent GB clients from economic downfall due to health issues. Through this program, GB provided affordable insurance not only to its members but also the non-members at a slightly higher price [21].

The social innovations in Bangladesh have been changing the rural life in Bangladesh since a series of programs were launched. Comparisons of development indicators and health outcome data between Bangladesh and its neighboring countries show the longest life expectancy (68.3), the lowest infant and under-5 mortality rates (0.042 and 0.051) and the lowest maternal mortality rate (0.00194) in Bangladesh despite of its highest poverty rate (32\%) [23]. The projects discussed above lead to improved health condition of rural women, which motivated them to be more productive and change their course of lives. Data show that in 1983, only $8 \%$ of the women population participated in economic activities in rural areas; whereas in 2011 it became 57\% [23]. Such dramatic improvement reveals the direct impact from social innovations such as the community based health service and MHI programs.

\section{Understanding the Social Innovations and the Success Factors in Bangladesh}

In the above discussed social innovations that greatly impacted the healthcare sector in Bangladesh, the NGOs, together with the government, served as the agent to sense the need and interact with the rural health system to monitor the social responses. Using the framework developed in [2], we try to explain the process of how these social innovations happened. As depicted in Figure 1, the agent, dominated by the NGOs in collaboration with government, communicates with the institution that includes the public and private healthcare providers as well as the rural families, regarding the new ideas or practices to explore the feasibility of them. In the innovation process, as the institutions are an integral part of the whole social system, through legitimate action, the information of the new ideas and practices is passed to the system. As more units in the institution adopt the new ideas or practices, the new practices or ideas in the implemented format become part of the collective norms, habits and the overall culture of the society. As a result, the implemented ideas or the practices become a successful social innovation.

In Bangladesh, besides the social innovation projects discussed in previous sections with a focus on the health-

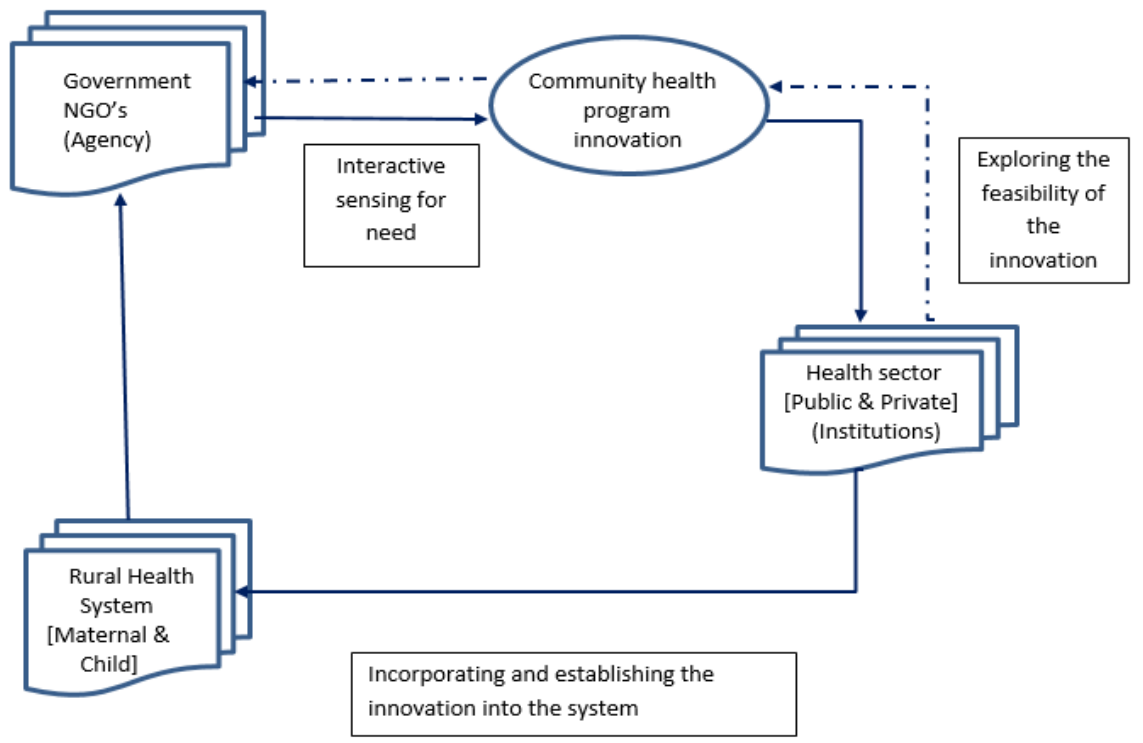

Figure 1. Bangladesh social innovation process in the healthcare sector. 
care sector, many others success stories have also been seen in different sectors. For example, in the communications sector, the village phone scheme launched by GB in 1997 aiming at providing modern telecommunication service to poor rural people have changed the way of community communication dramatically [24]. As a result of the village phone innovation, trades and exchanges increased in the rural communities, business relationships were getting stronger, and more effective decisions were made due to improved communications. Such economic empowerment also increased the family, social and gender index in those areas [25]. By the end of 1999, the village phones became a standard operation in more than 500 villages in Bangladesh. For another example, the pilot HMI scheme through BRAC and the HMI program by GK discussed in section 3.2 were part of the Women's Empowerment through Employment and Health (WEEH) project launched by ILO to assist poor women to access employment and income opportunities [18]. Besides making healthcare accessible and affordable to these women, the other major component of the WEEH project focused on providing and promoting decent employment for women while improving family and children's welfare, promoting gender equality, and strengthening women's participation and leadership in trade unions [26]. As noted earlier, women population participated in economic activities in rural areas increased dramatically from 8\% in 1983 to 57\% in 2011 [23] as a result of the WEEH project.

What factors have led to the huge success of social innovations in Bangladesh? What kind of environment can spur the wave of social innovations? What lessons that other countries, especially the ones with similar socioeconomic environment, can learn from Bangladesh? By looking at the different cases, we summarize our findings in three main areas:

1) A pluralistic environment featuring equality and government collaboration with NGOs: As mentioned earlier, the Bangladesh government has maintained a very friendly relationship with NGOs since independence, probably because it realized that they were very much needed [17]. Take the healthcare sector for example again: Even though substantial investment had been made by the government to develop the health infrastructure, the healthcare needs of the rural population had not been met successfully [21]. The interventions from NGOs like BRAC targeting certain issues and population through different projects were tolerated, and also encouraged and supported by the government to different degrees. Instead of creating an "idealized policy framework" at the birth of the country, the Bangladesh government welcomed many participants into the health sector to work together towards the same goal [27]. As a result, a pluralistic environment was created in Bangladesh featuring government collaborating with a huge number of NGOs and private organizations. In innovation management literature, it has been noted that a heterogeneous and dynamic environment is more likely to spark creative ideas and encourage innovations [28]. This is proved to be true for social innovations in Bangladesh too.

2) Government willingness for experimentations: For any innovation to succeed, lots of experimentations are needed [29]. Experimentations are essential for social innovators also to sense the need and explore the feasibility of different solutions. In the early stage of many social innovation projects initiated by NGOs like BRAC, pilot studies were conducted and impacts were analyzed [21] [30] before the projects were scaled up to benefit more population and got embedded into the social system. For example, the BRAC intervention project on improving Maternal, Neonatal and Child Survival (MNCS) was first piloted in one district in 2006 and then extended to three other districts in 2008 [31]. In the pilot project, besides the BRAC community health workers who provided services at the community level, the Bangladesh Ministry of Health and Family Welfare also provided support by improving emergency obstetric and newborn care services at the facility level [30]. The willingness and flexibility of the government to allow and support experimentations by the NGOs through various projects led to successful social innovations that speeded up health improvement in Bangladesh.

3) Continuous problem solving by creative and risk-taking agents: One executive interviewed in [29] stated that the way to boost innovations is to not innovate but solve problems. As mentioned earlier, social problems are regarded by many as the motivation for social innovations [5]. During the development process of a society, one big challenge is that solving one problem leads to another [17]. The reason BG founder created BK to add the MHI program was mainly to solve the problem of sick clients not being able to pay back the micro loan borrowed and getting into economic downturns without being able to get back on feet. The reason that BRAC became the world's largest NGOs and made great impact through its numerous social innovation projects was also to solve social problems that are interrelated. When BRAC found that a certain population still could not afford the community based healthcare facility when getting sick, it started the MHI program to make healthcare more affordable to people. It also took preventative initiative to advise people seeking for help when health problems first occur. BRAC got into food processing because it found out that its poor clients had difficulty selling animal 
products using the micro loan they got from BRAC’s microcredit program. It also set up programs to give animals to rural people who could not even got micro loan due to their extreme poverty [17]. During these continuous problem solving, being creativity and being willing to take risks, two attributes valuable to other types of innovators [29], are observed from agents that moved the social innovations forward in Bangladesh. Studies also show that the executives of the NGOs believe strongly in action than words and make great efforts in direct involvement in social development rather than developing corporate social disclosures [25].

\section{Conclusion}

Despite of the poor economic growth in the past 20 years, biggest gains in the basic condition of people's lives have been seen in Bangladesh than anywhere else [17]. The dramatic change lies in the success of social innovations happening in different sectors of the Bangladesh society. Through investigations of the healthcare sector in particular, we explored the critical factors that contributed to the success of the social innovations in Bangladesh. We conclude that social innovations flourish in pluralistic environment where experimentations are encouraged and multiple players who are creative and not afraid of risks are dedicated in continuous problem solving to address interrelated social issues. Great social innovators need to be leaders who are strong in action with a focus to improve the welfare of the affected population.

\section{References}

[1] Hellström, T. (2004) Innovation as Social Action. Organization, 11, 631-649.

[2] Cajaiba-Santana, G. (2014) Social Innovation: Moving the Field Forward. A Conceptual Framework. Technological Forecasting and Social Change, 82, 42-51.

[3] Nightingale, P. (1998) A Cognitive Model of Innovation. Research Policy, 27, 689-709.

[4] (2014) Situation of Newborn and Child Health in South-East Asia. W. H. Organization.

[5] Phills Jr., J.A., Deiglmeier, K. and Miller, D.T. (2008) Rediscovering Social Innovation. Stanford Social Innovation Review, 6, 34.

[6] Del Sesto, S.L. (1983) Technology and Social Change. Technological Forecasting and Social Change, 24, $183-196$.

[7] Henderson, H. (1993) Social Innovation and Citizen Movements. Futures, 25, 322-338.

[8] Dawson, P. and Daniel, L. (2010) Understanding Social Innovation: A Provisional Framework. International Journal of Technology Management, 51, 9-21. http://dx.doi.org/10.1504/IJTM.2010.033125

[9] Hancock, P. and Tyler, M. (2004) "MOT Your Life”: Critical Management Studies and the Management of Everyday Life. Human Relations, 57, 619-645.

[10] Baldwin, C.Y. and Clark, K.B. (1997) Managing in an Age of Modularity. Harvard Business Review, 75, 84-93.

[11] Howaldt, J. and Schwarz, M. (2010) Social Innovation: Concepts, Research Fields and International Trends: IMA/ ZLW.

[12] Mondal, P. (2014) Social System: Meaning, Elements, Characteristics and Types. http://www.yourarticlelibrary.com/sociology/social-system-meaning-elements-characteristics-and-types/8524/

[13] Abed, F.H. (2013) Bangladesh’s Health Revolution. The Lancet, 382, 2048-2049.

[14] (2016) Global Health Observatory Data Repository. World Health Organization.

[15] Ruhul, A.M., Fukuda, H., Nakajima, K., Takatorige, T. and Tatara, K. (1999) Public Health Services in Bangladesh with Special Reference to Systems and Trends of Vital Statistics. Environmental Health and Preventive Medicine, 4, 65-70. http://dx.doi.org/10.1007/BF02931996

[16] (2014) Annual Report 2012-2013 PDF. Bangladesh Ministry of Health and Family Planning.

[17] (2012) The Path through the Fields: Bangladesh and Development. The Economist, 405, 23(US).

[18] Ahmed, M.U., Islam, S.K., Quashem, M.A. and Ahmed, N. (2005) Health Microinsurance: A Comparative Study of Three Examples in Bangladesh. CGAP Working Group on Microinsurance_-Good and Bad Practices Case Study No. 13.

[19] Barber, B. (2002) No Free Lunch-Basics of BRAC (Bangladesh Rural Advancement Committee). The World and I.

[20] (2008) BRAC Health Programme: Breaking New Grounds in Public Health. BRAC, Dhaka.

[21] Hamid, S.A., Roberts, J. and Mosley, P. (2011) Evaluating the Health Effects of Micro Health Insurance Placement: Evidence from Bangladesh. World Development, 39, 99-411. http://dx.doi.org/10.1016/j.worlddev.2010.08.007 
[22] Grameen Kalyan Official Website, 16 April 2016. http://www.grameenkalyan-info.org/

[23] Chowdhury, A.M.R., Bhuiya, A., Chowdhury, M.E., Rasheed, S., Hussain, Z. and Chen, L.C. 2013) The Bangladesh Paradox: Exceptional Health Achievement despite Economic Poverty. The Lancet, 382, 1734-1745.

[24] Aminuzzaman, S., Baldersheim, H. and Jamil, I. (2003) Talking Back! Empowerment and Mobile Phones in Rural Bangladesh: A Study of the Village Phone Scheme of Grameen Bank. Contemporary South Asia, 12, 327-348.

[25] Momin, M.A. (2013) Social and Environmental NGOs’ Perceptions of Corporate Social Disclosures: The Case of Bangladesh. Accounting Forum, 37, 150-161. http://dx.doi.org/10.1016/j.accfor.2013.04.005

[26] (2005) Evaluation: Women's Empowerment through Employment and Health Project. International Labor Organization.

[27] Das, P. and Horton, R. Bangladesh: Innovating for Health. The Lancet, 382, 1681-1682.

[28] (2002) Innovation: Driving Product, Process, and Market Change. Jossey-Bass A Wiley Company.

[29] (2002) Inspiring Innovation. Harvard Business Review, 80, 39-49.

[30] Quayyum, Z., Khan, M.N.U., Quayyum, T., Nasreen, H.E., Chowdhury, M. and Ensor, T. (2013) “Can Community Level Interventions Have an Impact on Equity and Utilization of Maternal Health Care”-Evidence from rural Bangladesh. International Journal for Equity in Health, 12, 22.

[31] Nasreen, H.-E., Nahar, S., Al Mamun, M., Afsana, K. and Byass, P. (2011) Oral Misoprostol for Preventing Postpartum Haemorrhage in Home Births in Rural Bangladesh: How Effective Is It? Global Health Action, 4. 